\section{ARCHITECTURAL PRINCIPLES IN ARTHRODESIS}

By H. A. Brittain, O.B.E., M.A., M.Ch., F.R.C.S. and Edition. Pp. xi + r 96, with 257 illustrations, 9 in full colour. Edinburgh: E. \& S. Livingstone, Ltd. I952. $42 \mathrm{~s}$.

This is the second edition of a monograph that is already well known to orthopaedic surgeons. The author's most important contribution is undoubtedly his method of ischio-femoral arthrodesis, which has stood the test of time and proved its value, especially in the treatment of tuberculous arthritis of the hip. The technique of this operation, slightly modified since the first edition, is fully described and well illustrated. In this edition there also appears, for the first time, a detailed account of a new method of ischio-femoral fusion-the Varthrodesis-which is giving promising results in non-destructive lesions of the hip joint, especially osteoarthritis. The method combines rigid fixation of the joint, by a long nail driven across it, with insertion of a stout bone graft through a wide-bore drill hole in the femur into the ischium; osteotomy is avoided and early weight-bearing is permitted, seemingly without prejudicing the chances of fusion. The results of these two methods of arthrodesis of the hip suggest that Mr. Brittain's main 'architectural principle'-that a bone graft in compression is more likely to succeed than one in tension-is sound.

The section devoted to arthrodesis of the shoulder is a further notable contribution. Again the technique is such that a stout bone graft bridging the joint is under compression stress, the graft in this case being placed between the upper part of the shaft of the humerus and the axillary border of the scapula. Similar principles have been applied in the fusion of other joints, but on the whole the case for them is less convincing than it is in the hip and shoulder.

A number of criticisms must be made; the style is in places loose and the use of anatomical nomenclature inconsistent. Mistakes in the text and legends suggest a somewhat perfunctory reading of the proofs. No doubt the profusion of illustrations and the use of colour blocks are responsible for high costs. By suitable economies the book could perhaps have been produced at a price more consistent with its 70 pages of text, without detriment to its practical value. The younger surgeon, to whom it is chiefly of interest, would then have been more tempted to purchase it rather than to borrow it from the library.

\section{LAW RELATING TO HOSPITALS AND KINDRED INSTITUTIONS}

\section{Supplement to 1949 (Second) Edition}

By S. R. Speller, LL.B. Pp. viii +87 . London: H. K. Lewis \& Co., Ltd. I95I. I2s. 6d.

This little book sets out the additions to and changes in the law relating to hospitals caused by acts of Parliament, statutory rules and orders, $\frac{\varrho}{z}$ decisions of the Courts and circulars from the Ministry between 1949 and 1951 . It professes to be only a supplement, not an independent work, and the new material is arranged under references $\overline{\bar{s}}$ to the pages of the main book. The supplement, $\vec{\sigma}$ dealing with some important developments in the law relating to hospitals, is a most useful addition $\frac{\bar{\sigma}}{\bar{D}}$ to the main book, which should not now be used without it.

\section{CIBA FOUNDATION COLLOQUIA ON ENDOCRINOLOGY}

\section{Volume II. Steroid Metabolism and Estimation}

General Editor for the Ciba Foundation, G. E. W. Wolstenholme, O.B.E., M.A., M.B., B.Ch., assisted by MARGARET P. CAMERON, M.A., $\infty$ A.B.L.S. Pp. xix +429 , with 96 illustrations. London: J. \& A. Churchill, Ltd. 1952. 35s. O

This book is written for the steroid biochemist and the clinical endocrinologist and both will find the more recent methods and investigations described in detail and well documented. The dis- 5 cussion of experts unfolds the complex pattern of steroid metabolism. This is of real practical $\nabla$ interest to the clinician who uses ACTH and the $\overparen{\mathbb{D}}$ consultant who directs the investigation of endo $\frac{1}{3}$ crine cases; though it must be realized that the ${ }_{0}$ reader is left to draw his own conclusions. In th connection it is perhaps a little unfortunate tha $\overrightarrow{0}$ some authors appear to be over-enthusiastic in the $N$ clinical value they attach to their results, part ticularly in respect of pregnancy diagnosis. The methods of assay are mostly discussed by the authors themselves, and as is only possible in the verbatim report of a tête-à-tête meeting all the interesting 'side-shows' of the methods are $\triangle$ brought to light.

In criticism of the book, one would have liked to see some of the formulae better drawn, but on the whole the production is free from errors. The wealth of material and the reasonable price make it an attractive proposition.

E.K.

\section{MODERN PRACTICE IN TUBERCULOSIS}

\section{Vols. I and II}

Edited by T. Holmes Sellors, M.A., D.M., 웅 M.Ch., F.R.C.S., and J. L. Livingstone, M.D., F.R.C.P. Pp. xxxiv + 942, with 266 illustrations, 3 in colour. London: Butterworth \& Co. 1952. $£ 77$ s. for the two vols.

Few branches of medical practice have witnessed $N$ more far-reaching developments in the last ten $\mathrm{N}$ years than the diagnosis and treatment of chest dis- $\omega$ orders. In none has the work of the physician and surgeon become more closely knit. This is par- 0 ticularly true of tuberculosis. In this disease the $\mathbb{D}$ range of the surgeon's interest has steadily increased $\stackrel{?}{-}$ pari passu with the greater reliance which he has 0 been able to place upon the intelligent use of modern

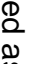

